\title{
Can antiviral treatment for hepatitis $C$ be safely and effectively delivered in primary care?
}

\author{
A narrative systematic review of the evidence base
}

\begin{abstract}
\section{Background}

The burden of hepatitis C ( $\mathrm{HCV}$ ) treatment is growing, as is the political resolve to tackle the epidemic. Primary care will need to work more closely with secondary care to succeed in reducing the prevalence of chronic HCV.
\end{abstract}

\section{Aim}

To identify research relating to the provision of antiviral treatment for $\mathrm{HCV}$ in primary care.

\section{Design and setting}

A narrative systematic review of six databases.

\section{Method}

Medline, Embase, Cinahl, PsycINFO, Web of

Science, and Cochrane were searched. Relevant journals were searched by hand for articles to be included in the review. Reference lists of relevant papers were reviewed and full-text papers were retrieved for those deemed to potentially fulfil the inclusion criteria of the review.

\section{Results}

A total of 683 abstracts led to 77 full-text articles being retrieved, of which 16 were finally included in the review. An evidence base emerged, highlighting that community-based antiviral treatment provision is feasible and can result in clinical outcomes comparable to those achieved in hospital outpatient settings. Such provision can be in mainstream general practice, at community addiction centres, or in prisons. GPs must be trained before offering such a service and there is also a need for ongoing specialist supervision of primary care practice. Such training and supervision can be delivered by teleconference, although, even with such ready availability of training and supervision, only a minority of GPs are likely to want to provide antiviral treatment.

\section{Conclusion}

There is emerging evidence supporting the effectiveness of antiviral treatment provision for patients with chronic hepatitis $C$ in a wide variety of primary care and wider community settings. Training and ongoing supervision of primary care practitioners by specialists is a prerequisite. There is an opportunity through future research activity to evaluate typologies of patients who would be best served by primary care-based treatment and those for whom hospital-based outpatient treatment would be most appropriate.

\section{Keywords}

general practice; hepatitis C; pegylated interferon; primary care; ribavirin.

\section{INTRODUCTION}

Hepatitis C virus (HCV) infection is a silent epidemic; late effects of chronic hepatitis C $(\mathrm{CHC})$ can include end-stage liver disease and require transplantation, as well as hepatocellular carcinoma, which becomes evident approximately 20-30 years after the infection has been acquired. It is estimated that 260000 people have acquired HCV in the UK, of whom 215000 have CHC; intravenous drug use is by far the most common route of acquisition. ${ }^{1}$ The World Health Organization gives the global prevalence for hepatitis C exposure as $3 \%$, with 170 million people affected and 3-4 million new infections annually.

Effective treatment exists in the form of weekly injections of pegylated interferon $\alpha-2 a$ and $2 b$ with daily, oral ribavirin; however, the patient group most likely to acquire the HCV through drug use is the group least likely to engage with secondary care for treatment. ${ }^{3}$ This poor engagement is multifactorial, but chaotic lifestyles and social exclusion are likely contributors. Furthermore, in the UK and US there are insufficient numbers of consultants and nurse specialists in infectious diseases, hepatology, and gastroenterology to cope with the enormous numbers of patients who have $\mathrm{CHC} .^{4}$

The opportunity to treat hard-to-reach patients for $\mathrm{CHC}$ in prison has been recognised for several years. Skipper et al reported their evaluation of a prison outreach clinic in 2003, ${ }^{5}$ concluding that

IF Brew, FRCGP, GPwSI in hepatitis C; C Butt, BSc, PGDip laddiction studies), PGDip (health research), clinical research fellow; N Wright, PhD, FRCGP, clinical director of Leeds Prison Healthcare Department, HMP Leeds, Leeds.

\section{Address for correspondence}

Dr lain Brew, Healthcare Department, HMP

Leeds, Leeds Community Healthcare NHS Trust, 2 Gloucester Terrace, Armley, Leeds, LS12 2TJ. there was an opportunity to treat patients, but low uptake and a large proportion of exclusions under the then-current guidelines meant the impact was limited. However, the 2013 Health Protection Agency (HPA) report recommends that testing and treatment in prisons be strengthened.

Primary care has successfully taken the lead on a number of chronic diseases such as diabetes, chronic obstructive pulmonary disease, and asthma, while shared care for disease-modifying, antirheumatic drugs has placed more responsibility on GPs for blood-test monitoring of drugs with potentially dangerous toxicity. ${ }^{6}$ Such developments in community-care delivery suggest that, with suitable training and support, GPs are able to support secondary care colleagues by taking over the care of selected cases of many other chronic conditions, thereby increasing the availability of treatment for hard-to-reach groups.

As early as 2001, Kivlahan and Chavey suggested that, in view of the size of the HCV epidemic, treatment of hepatitis C would become a routine aspect of primary care. ' Budd and Robertson endorsed this view in the UK in 2005, suggesting that increased screening and diagnosis would swamp the current secondary care-based services. $^{8}$

Further barriers to offering treatment in secondary care have been identified as homelessness, poverty, lack of information about the benefits of treatment, chaotic

E-mail: iainbrewanhs.net

Submitted: 4 January 2013; Editor's response: 11 February 2013; final acceptance: 12 August 2013.

(B)itish Journal of General Practice

This is the full-length article (published online 25 Nov 2013 of an abridged version published in print. Cite this article as: Br J Gen Pract 2013; DOI: 10.3399/bjgp13X675421 


\section{How this fits in}

The burden of liver disease is increasing in the UK and increasing prevalence of hepatitis $\mathrm{C}(\mathrm{HCV})$ is a recognised contributor to this trend. Current secondary care provision is difficult to access for a number of high risk groups and is under-resourced to tackle the estimated 215000 patients with chronic HCV. Primary care is well-placed to offer support and this paper brings together the international experience of treating chronic $\mathrm{HCV}$ in the primary care setting.

lifestyles, and fear of both health care and the criminal justice system, leading Gardenier and Alfandre to suggest primary care services as being pivotal in increasing access to such previously excluded groups. ${ }^{9}$ Edlin et al commented in 2005 that a growing number of methadone programmes, infectious-diseases clinics, and prisons were integrating hepatitis $\mathrm{C}$ care successfully. ${ }^{10}$

In 2007, Zevin identified the need to train more US primary care physicians in the treatment of hepatitis $C$ due to the insufficient numbers of secondary care specialists. ${ }^{4}$ Training the primary care workforce is key to primary care taking on this extended role; in the UK, the Royal College of General Practitioners has developed certificates in the detection, diagnosis, and management of hepatitis $B$ and $C$ in primary care to reinforce these educational messages. ${ }^{11}$ Such training has been a response to the marked increase

\section{Box 1. Example of Medline search strategy}

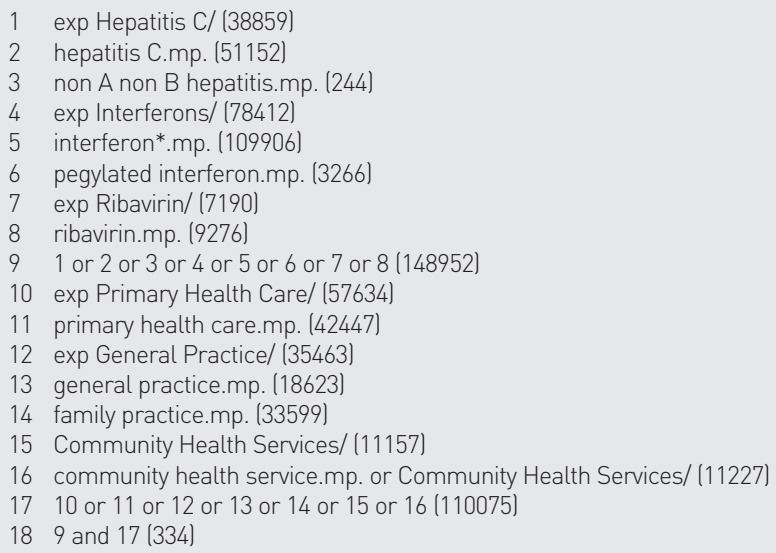

Figures in brackets are papers found. over the past 20 years in the number of GPs in the UK taking on a large part of the workload that relates to the management of substance misuse and opioid substitutes increasingly being prescribed in the primary care setting. ${ }^{12}$

Awareness has further been raised in primary care through the publication of guidance documents such as the Department of Health's 2004 Hepatitis C: Essential Information for Professionals and Guidance on Testing ${ }^{13}$ and the 2007 Substance Misuse Management in General Practice (SMMGP) Guidance for the Prevention, Testing, Treatment and Management of Hepatitis C in Primary Care, ${ }^{14}$ which have informed primary care practitioners about hepatitis C. With such an increase in educational and awarenessraising activity in the management of blood-borne viruses in primary care, it was considered appropriate to undertake a systematic review to identify empirical and descriptive research that evidences the delivery of antiviral therapy in primary care throughout the international community.

\section{METHOD}

\section{Search strategy}

The medical databases Medline, Cinahl, PsycINFO, Cochrane, Web of Science, and Embase were searched using the umbrella search terms "hepatitis C, ribavirin and pegylated interferon, primary care, family practice, general practice'. A full copy of the search strategy is available from the authors on request. The databases were searched from 1 January 2000 to 13 July 2011 and, following initial peer-reviewer comments, re-run from 13 July 2011 to 20 June 2013. An example of one search strategy is given in Box 1 .

\section{Inclusion criteria}

Papers dealing directly with hepatitis C drug treatment with pegylated interferon and ribavirin in primary care and primary care management of adverse effects during antiviral therapy were included. This included papers where antiviral treatment for hepatitis $\mathrm{C}$ was either initiated or maintained by GPs in the community (that is, non-specialist settings, which include mainstream general practice, GP-led prison services, or GP-led community drug services).

\section{Exclusion criteria}

Papers that were published pre-2000 were excluded because combination treatment was only licensed in 1998 and antiviral treatment was exclusively a specialist role. 


\section{Box 2. Criteria used to assess the quality of the studies}

- Clear case definition of hepatitis C treatment

- Clear case definition of primary care or community (such as non-hospital) settings

\section{Randomised controlled studies}

- Process of randomisation clearly described and whether open, single blind, or double blind

- Process of concealment clearly described

- Steps taken to avoid contamination

- Steps taken to ensure independence of data analysis from the clinical intervention

- Clear explanation of how missing data was accounted for, for example, use of intention-to-treat analysis or multiple imputation methods

\section{Quasi-experimental studies}

- Baseline data reported

- Potential for selection bias described and accounted for in the analysis

- Potential for confounders described and accounted for in the analysis

- Steps taken to ensure independence of data analysis from the clinical intervention

\section{Observational cohort studies}

- Use of a control group

- Potential confounders described with an attempt made to quantify the effect, either by study design or by statistical analysis

- Potential for loss to follow-up bias described and accounted for in the analysis

\section{Qualitative studies}

- Clear explanation of conceptual framework

- Explicit methods of sampling described

- Explanation of whether data saturation was obtained

- Clear explanation of approaches taken to data analysis

Papers were also excluded if they:

- dealt exclusively with antiviral treatment in secondary care;

- dealt with interferon monotherapy or combination therapy, in which the interferon was not pegylated; or

- evaluated specialist-only treatment provision in the primary care setting.

Following peer-review comments, papers in which the outcome was changes in either GP knowledge or attitudes towards

provision of antiviral treatment for hepatitis C were also excluded.

\section{Study selection}

Using inclusion and exclusion criteria, identified abstracts were assessed for relevance independently by two of the researchers; discrepancies were resolved by consensus between all three researchers. Following this process, full papers were retrieved for review by one of the researchers. Papers were considered as empirical research, descriptive research, commentary, or opinion pieces. Commentary and opinion pieces were excluded so that only empirical and descriptive research findings were included in the final review (Table 1). Relevant journals were hand-searched for pertinent articles and reference lists of these were reviewed for additional relevant papers. Box 2 highlights the criteria used to assess the quality of the evidence.

\section{RESULTS}

As highlighted in Figure 1, a total of 683 abstracts were identified using the search terms, including 33 duplicates. Of these, 573 were excluded by consensus between the authors and 77 papers were obtained in full for review. Sixteen papers were included in the review (Table 1). Primary outcomes measured included treatment initiation, maintenance or completion, or sustained virologic response (SVR). Twelve papers related to the mainstream primary care setting, three to treatment provision in the custodial setting, and one to both mainstream primary care and custodial provision.

\section{Antiviral treatment provision in the primary care setting}

Four Canadian studies have demonstrated

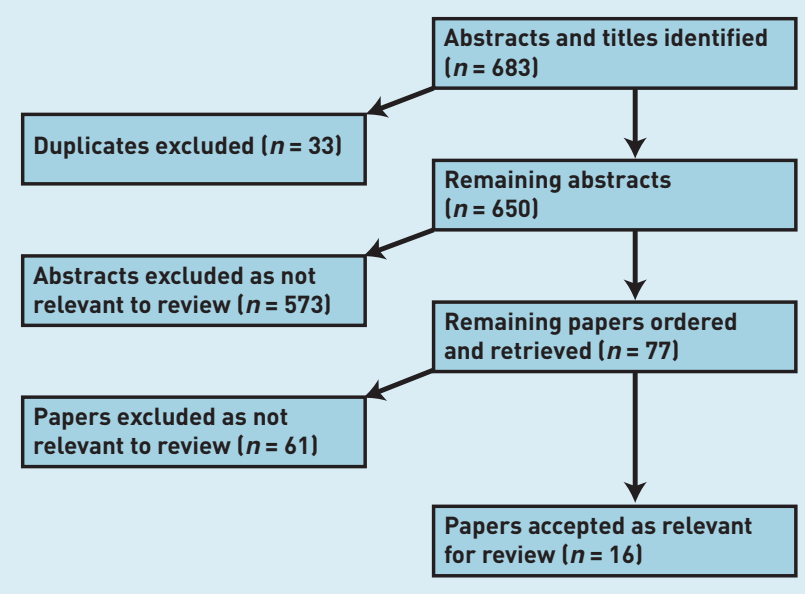




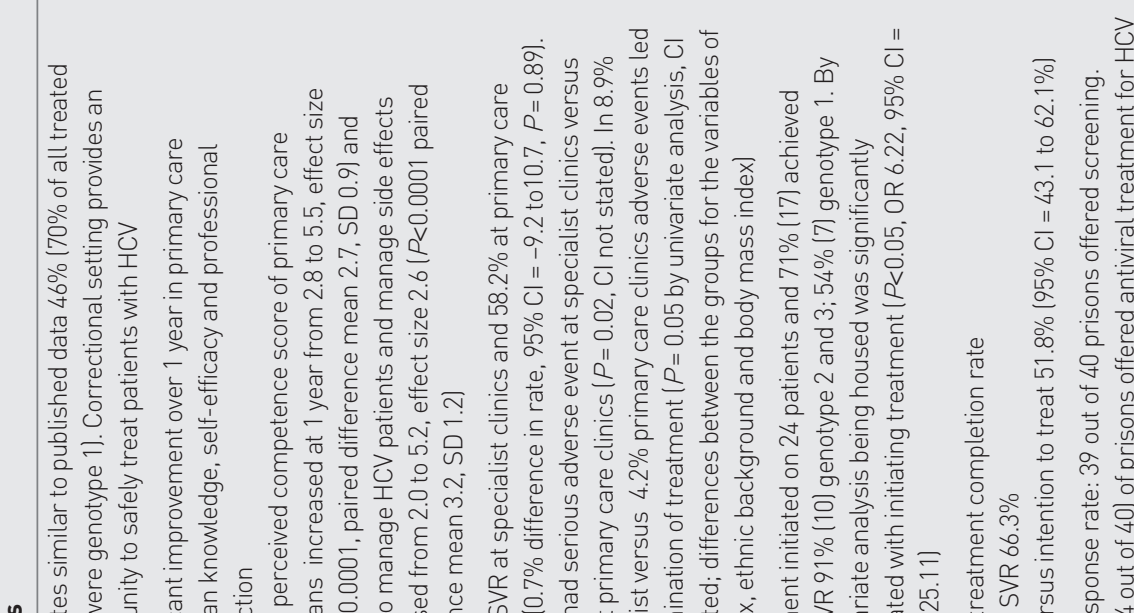

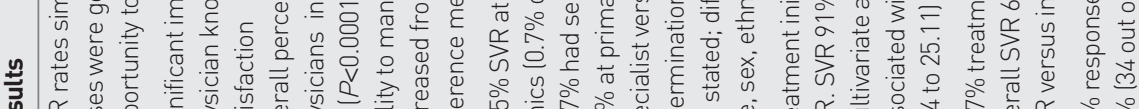

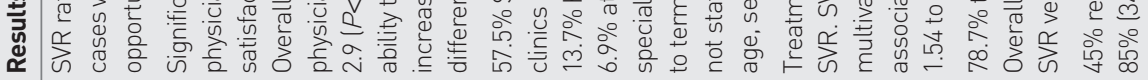
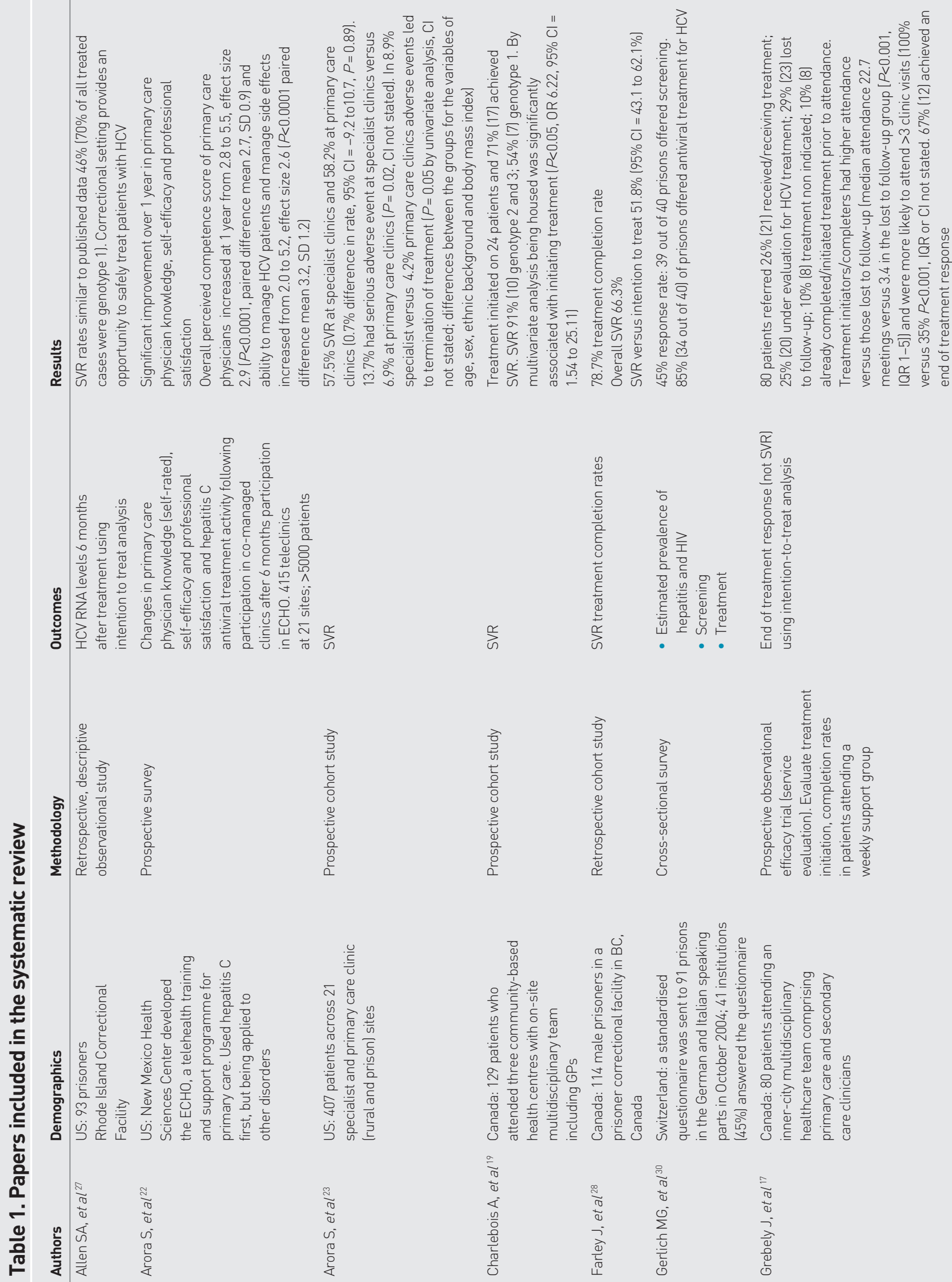


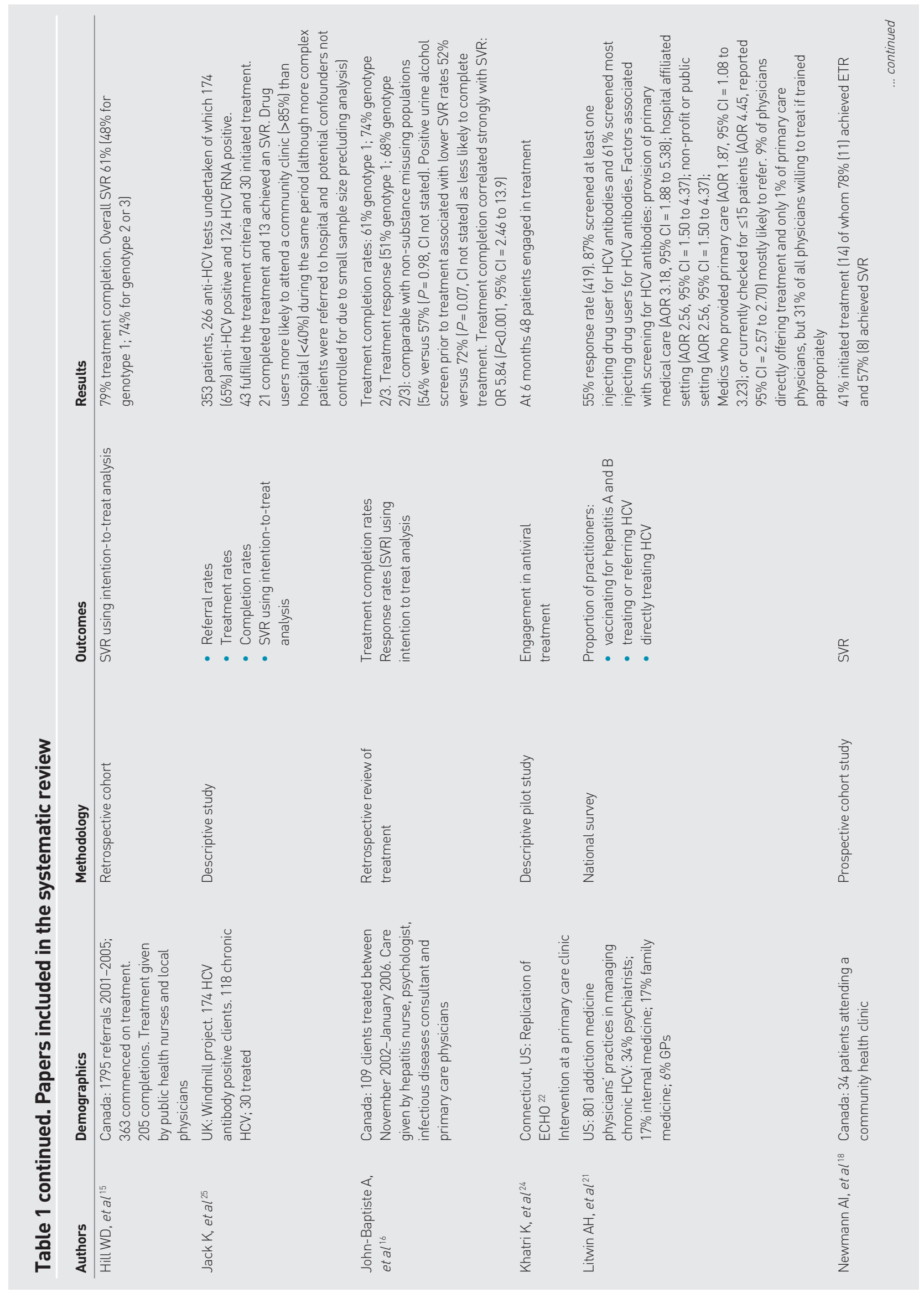




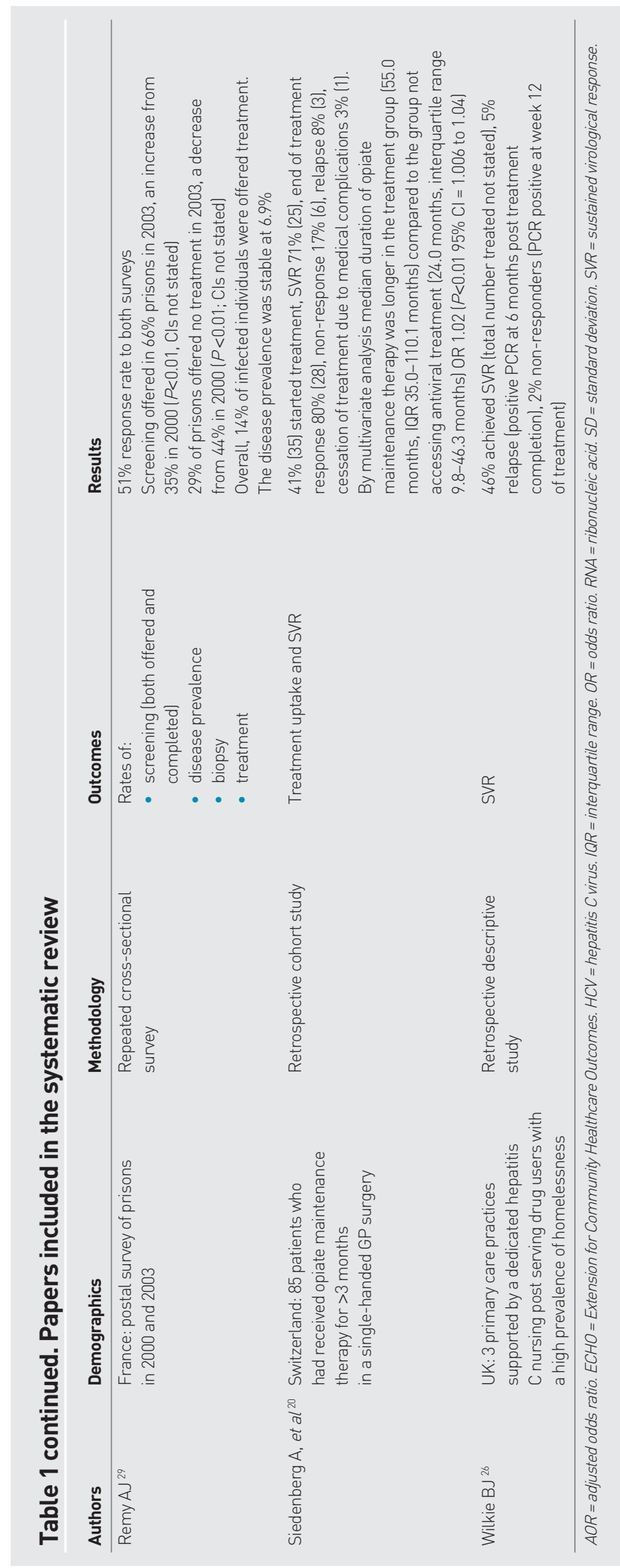

the feasibility and effectiveness of community-based antiviral treatment provision among individuals who inject drugs. The largest study conducted by Hill et al evaluated the outcomes of treatment provision to 1795 individuals at four community centres in rural and small urban settings. ${ }^{15}$ Treatment was initiated to a total of 390 patients and outcomes were available for 205 patients. The overall SVR in these 205 patients was $61 \%$. This study was a primary care model in that patients could self-refer into treatment; however. the paper was not explicit as to whether the physician involvement was by GPs or limited to specialist clinicians.

The following year, the second Canadian study conducted by John-Baptiste et al evaluated antiviral treatment provision in primary care-based community addictiontreatment centres. ${ }^{16}$ Key findings from a cohort of 109 patients demonstrated treatment completion rates of $61 \%$ and $74 \%$ for genotypes 1 or 4 and 2 or 3 respectively. Treatment response rates analysed by intention to treat were $51 \%$ and $68 \%$ for genotypes 1 or 4 and 2 or 3 respectively. Positive urine toxicology indicating use of illicit drugs in the 6 months prior to treatment was significantly associated with lower rates of treatment completion but not lower rates of SVR. A positive urine screen indicating the use of alcohol prior to therapy was associated with both lower rates of treatment completion and lower rates of response. The authors concluded that treatment completion and response rates were comparable to populations who do not misuse substances.

The finding of the feasibility of communitybased treatment provision to those who inject drugs is confirmed by another Canadian study conducted by Grebely et al. ${ }^{17}$ Community-based treatment provision to such individuals was through a multidisciplinary team model comprising both primary and secondary care clinicians. Of the participants, $65 \%$ achieved an end of treatment response (ETR) despite the fact that three-quarters of all recruited patients reported ongoing drug use. In those who completed treatment, virological response at the end of treatment was $67 \%, 100 \%$, and $57 \%$ for genotypes 1, 2, and 3 respectively. However, numbers were small as only 18 patients were recruited to the study.

Newman etalcarried out a Toronto-based study in 2011 of "high-risk, marginalised, and traditionally underserved' patients with $\mathrm{HCV}$. They treated 14 out of a sample of 34 patients and, of these, 11 completed treatment with eight achieving SVR. Again, 
small numbers was a feature of the study, but further evidence of the potential for success was demonstrated. ${ }^{18}$

The evidence would suggest that support needs to be offered to those who use drugs to engage with, and remain in, primary care-based treatment. Charlebois et al reported the effects of peer support in a multidisciplinary team in Toronto. ${ }^{19}$ Of 110 eligible patients, treatment was initiated in 24; of these, 13 had genotype $1 \mathrm{HCV}$ and seven (54\%) achieved SVR compared with $10(91 \%)$ out of 11 with genotype 2 or 3. The authors concluded that active drug use was not necessarily a contraindication to HCV treatment when supported with psychosocial support and accessible health care. $^{19}$

In addition to psychosocial support, it would appear that linking treatment to opioid maintenance therapy increases treatment uptake and completion. Seidenberg et al showed that it was feasible for GPs offering opiate substitution treatment to provide antiviral treatment to patients with $\mathrm{HCV} .{ }^{20}$ Antiviral therapy was provided to 35 suitable patients out of a total of 85 who were receiving opiate replacement therapy. Forty patients declined the offer of treatment and the remaining 10 were deemed unfit for other health reasons. An SVR rate of $71 \%$ was achieved.

Although these studies provide support for the provision of antiviral treatment in the primary care setting, the need for prior training is a necessary prerequisite. Litwin et al found that, although only $1 \%$ of primary care physicians were treating $\mathrm{CHC}$, $13 \%$ were willing to do so with appropriate training. ${ }^{21}$

Novel ways of training primary care staff are emerging. Through Project ECHO Extension for Community Healthcare Outcomes), the University of New Mexico in the US evaluated a teleconferencing approach whereby primary care clinicians meet weekly with specialists via teleconference. ${ }^{22}$ Support is provided to facilitate primary care practitioners in offering antiviral treatment to patients who are hepatitis C positive. Primary care practitioner self-rated knowledge and treatment activity was surveyed in 415 teleclinics at 21 sites. Results showed a statistically significant increase in perceived competence scores during the course of the project. Clinical outcomes of Project ECHO were reported in 2011,23 in total, 407 patients treated for hepatitis $C$ resulted in a $58.2 \%$ overall SVR rate compared with a rate of $57.5 \%$ that had been reported at the University of New Mexico's specialist hepatitis C clinic. The authors concluded that implementation of this model would allow other states and nations to treat a greater number of patients infected with HCV than they are currently able to treat. The Project ECHO model was replicated as a pilot project in Connecticut, US, with the primary outcome being treatment engagement; 48 patients were engaged in treatment at the 6-month time-point. ${ }^{24}$

In 2008, the Windmill Project in the UK reported on the community-based treatment of 30 patients with $\mathrm{CHC}$. The service was based around a specialist nurse from secondary care working with drug workers and GPs. The evaluation found that patients were twice as likely to attend their antiviral treatment appointments at the primary care clinic as those referred to secondary care during the same period. ${ }^{25}$ Similar SVR rates were reported, although these were not statistically significant due to low numbers.

The possible effectiveness of a specialist nurse to support GPs was highlighted in the study by Wilkie. ${ }^{26}$ In this model, an experimental, nurse-led community hepatitis C service was conducted; it was funded by practice-based commissioning savings and based in three general practices in Liverpool. An SVR rate of $46 \%$ was reported with $19 \%$ of participants failing to complete treatment. At the time the paper was submitted, $17 \%$ of patients were still in treatment or awaiting results. The remaining $18 \%$ were lost to followup $(3 \%)$, relapsers $(5 \%)$ or other outcome (10\%).

\section{Antiviral treatment provision in custodial settings}

Service evaluations of prison-based antiviral treatment have been conducted in the US $^{27}$ and Canada, ${ }^{28}$ where SVR rates using intention-to-treat analysis was $48 \%$ (70\% genotype 1) and $51.8 \%$ respectively. Both studies concluded that correctional facilities provided an ideal opportunity to diagnose and treat patients with $\mathrm{CHC}$ in combination with preventative measures.

A repeated cross-sectional survey of treatment provision in more than 80 French prisons was conducted by Remy in 2000 and 2003; over that time, provision increased from 164 patients receiving treatment in 2000 to 297 patients receiving treatment in $2003 .{ }^{29}$ The number of prisons offering no treatment' reduced from $44 \%$ in 2000 to $29 \%$ in 2003.29

A cross-sectional survey of treatment coverage in Swiss prisons was conducted by Gerlich et al in $2004 .{ }^{30} \mathrm{In}$ total, 41 prisons 
responded to the survey and key findings were that antiviral treatment provision was possible in $85 \%$ of them. However, treatment discontinuation on release was identified as a significant barrier to treatment completion. In response to this barrier, five institutions reported not offering antiviral therapy to patients who had less than 6 months of their sentence to serve due to the high risk of completion failure.

\section{DISCUSSION}

\section{Summary}

The HPA recommend in its 2013 report:

Commissioners should consider expanding provision of treatment in nontraditional settings, including primary care, drug treatment settings and prisons, to make treatment more accessible for individuals and thereby reduce the potential for transmission."

There is published evidence that the current provision for delivering antiviral treatment to patients with $\mathrm{CHC}$ is inadequate in many countries around the world, including the UK. Several commentators have recommended that antiviral therapy can, and should, be delivered in the multidisciplinary primary care setting when focused on areas of high prevalence of HCV. $4,8-10,15,17,27-28$ The findings of the current review have suggested that such primary care-based treatment is feasible with support from specialists. Such a model has treatment outcomes that are equivalent with secondary care services. However, providing such a model across the whole of the primary care treatment system will require an extensive programme of education of GPs.

There have been several studies showing the non-inferiority of antiviral therapy in primary care $e^{15,16,25}$ and prisons, ${ }^{27,28}$ but further studies are needed to demonstrate the non-inferiority of SVR from antiviral therapy delivered in each of the various primary care environments, compared with secondary care. Furthermore, the heterogeneous nature of primary care will require the comparison of the various piloted models of care for cost-effectiveness in each setting so that appropriately evidenced business cases may be produced for these new services. This review has highlighted recent evidence from the UK of savings from practice-based commissioning being used to provide specialist-nurse support for GPs willing to prescribe. ${ }^{26}$

Before primary care-based antiviral treatment for $\mathrm{CHC}$ can become a mainstream reality in the UK, further training is required to increase GPs and other primary care workers' knowledge of hepatitis C management, and referral pathways with appropriate exclusion criteria need to be developed. It could be that novel approaches to training need to be considered, particularly for GPs working in rural settings. For example, US research compared the impact of videoconferencing with standard lecturing on 175 primary care providers Iprimary care physicians, nurses, physicians assistants, and nurse practitioners) using a 10-point quiz before and after videoconferencing. All groups demonstrated a statistically significant improvement in their scores post videoconferencing leading the authors to conclude that such training has the potential to eliminate the geographical and economic barriers to professional education' for rural practitioners or those who are otherwise isolated. ${ }^{31}$

The RCGP has successfully delivered certificate courses in the detection and diagnosis of hepatitis B and C. ${ }^{11}$ The Certificate 2 course is delivered through a learning log, which is based on case studies and clinic attendances with specialist mentors and tutors. Successful completion of the course will give primary care practitioners the confidence to support secondary care colleagues in delivering treatment to the most appropriate cases. In time, this confidence may translate into local antiviral treatment services based in primary care, but there will need to be robust links with specialist clinics for clinical governance purposes.

In the past 12 months, new triple therapy' treatment protocols have been licensed and appraised by the then National Institute of Health and Clinical Excellence $(\mathrm{NICE})^{32,33}$ with the potential for new side-effect profiles, including rashes and marked anaemia. The addition of protease inhibitors telaprevir and boceprevir to treatment protocols for genotype 1 $\mathrm{HCV}$ means that close haematological monitoring is of even more importance than with pegylated interferon and ribavirin alone. As such, an ongoing educational and competency framework must be developed to permit the safe and effective delivery of current antiviral therapies in the primary care setting. The Department of Health document Implementing Care Closer to Home: Convenient Quality Care for Patients ${ }^{34}$ and its programme of re-accreditation would present an ideal framework for accreditation for practitioners with special interest in viral hepatitis. 
The findings of this review have also highlighted that custodial settings can be an ideal place to initiate antiviral treatment. However, there is a risk of discontinuation on release from prison; so much so that antiviral treatment can be withheld from patients on short sentences. There is a pressing need to develop and evaluate treatment models that allow for the initiation of antiviral treatment in custodial settings, which is continued in the community at the point of the patient's release from prison. In England, an estimated 27500 patients were treated between 2006 and 2011 with pegylated interferon as part of NICE-recommended combination therapy; this equated to treating approximately $3 \%$ of those who are chronically infected per year.' France has recorded higher treatment rates, including $14 \%$ across a number of French prisons. ${ }^{29}$

\section{Strengths and limitations}

At present, there is little published evidence about GPs delivering antiviral therapy, particularly in the UK. Numbers treated in studies such as the Windmill Project were small, so lacked statistical power. ${ }^{25}$ The strengths of this review were the synthesis for the first time of the literature pertaining to the feasibility of providing antiviral treatment for hepatitis $\mathrm{C}$ in the primary care setting. A comprehensive systematic review of the key databases was undertaken.

\section{Comparison with existing literature}

The findings of this systematic review pertaining to the feasibility of such primary care provision concur with both opinion pieces expressing the potential of primary care to increase availability of this important treatment and also wider empirical literature highlighting that with training GP s feel more confident in offering this treatment.

\section{Implications for practice}

The findings from this review of the international evidence base would suggest that primary care services deliver results equivalent to secondary care among hard-to-reach groups. Further adequately powered studies will help to underpin the work already published. There are likely to be a variety of primary care models delivering such antiviral treatment though all will require support from local specialist services. For experienced GPs who have large numbers of drug using patients (for example those working in prison or primary care community drug service settings) they are likely to initiate, continue and complete prescribing regimes for large numbers of patients with support in the form of clinical supervision from specialist services. However for GPs in mainstream practice with small numbers of drug using patients, the treatment model is more likely to be akin to traditional shared care models for other chronic diseases Ifor example, provision of insulin to those with diabetes, or disease modifying antirheumatic drugs for rheumatoid arthritis). However regardless of the model, it is hoped that this review will encourage more GPs to become involved in this important and rapidly developing area of health care.

\section{Competing interests}

Dr lain F Brew was involved in the development of the Royal College of General Practitioners certificates in hepatitis B and $\mathrm{C}$ and received payments for his work as tutor and examiner. He has also received honoraria from Janssen for delivering meetings about hepatitis C in the UK. All other authors have declared no competing interests.

\section{Acknowledgements}

The authors gratefully acknowledge Philippa Hearty, Beverley Berry, and Richard Daly of the RCGP library, as well as Helen Swales and staff at the library services of Leeds Community Healthcare NHS Trust for their assistance in retrieving the documents for this literature review.

\section{Discuss this article}

Contribute and read comments about this article on the Discussion Forum: http://www.rcgp.org.uk/bjgp-discuss 


\section{REFERENCES}

1. Health Protection Agency Centre for Infections, Health Protection Scotland, Public Health Wales, Health \& Social Care Board Northern Ireland. Hepatitis C in the UK: 2013 report. http://umw.hpa.org.uk/Publications/InfectiousDiseases/ BloodBornelnfections/HepatitisCInTheUK/1307HepatitisCintheUK2013report/ laccessed 3 Nov 2013).

2. World Health Organization. Hepatitis C. Fact Sheet 164. 2013. http://unw.who. int/mediacentre/factsheets/fs164/en/ (accessed 3 Nov 2013).

3. Jowett SL, Agarwal K, Smith BC, et al. Managing chronic hepatitis $\mathrm{C}$ acquired through intravenous drug use. QJM 2001; 94(3): 153-158

4. Zevin B. Managing chronic hepatitis $\mathrm{C}$ in primary care settings: more than antiviral therapy. Public Health Reports 2007; 2 (122 Suppl): S78-S82.

5. Skipper C, Guy JM, Parkes J, et al. Evaluation of a prison outreach clinic for the diagnosis and prevention of hepatitis $\mathrm{C}$ : implications for the national strategy. Gut 2003; 52: 1500-1504.

6. Scott, DL, Symmons DPM. The role of specialists in managing established rheumatoid arthritis. Rheumatology 2008; 47(3): 237-238.

7. Kivlahan C, Chavey W. What are the current treatment and monitoring recommendations for hepatitis C virus (HCV). J Fam Pract 2001; 50(11): 928 929.

8. Budd J, Robertson R. Hepatitis C and general practice: the crucial role of primary care in stemming the epidemic. Br J Gen Pract 2005; 55(513): 259-260.

9. Gardenier D, Alfandre D. Primary care of the patient with chronic hepatitis C. J Nurse Pract 2006; 2(8): 517-524.

10. Edlin BR, Kresina TF, Raymond DB, et al. Overcoming barriers to prevention, care, and treatment of hepatitis C in illicit drug users. Clin Infect Dis 2005; 5 (40 Suppl): S276-S285

11. Royal College of General Practitioners and Health Protection Agency. RCGP Certificate in the Detection, Diagnosis and Management of Hepatitis B and C in Primary Care Part 2 Programme Handbook. London: RCGP, 2012.

12. Strang J, Sheridan J, Hunt C, et al. The prescribing of methadone and other opioids to addicts: national survey of GPs in England and Wales. Br J Gen Pract 2005; 55(515): 444-451.

13. Department of Health. Hepatitis C: Essential information for professionals and guidance on testing. London: DoH, 2004

14. Royal College of General Practitioners. Guidance for the prevention, testing, treatment and management of hepatitis $C$ in primary care. 1st edn. London: RCGP, 2007.

15. Hill WD, Butt G, Alvarez M, Krajden M. Capacity enhancement of hepatitis C virus treatment through integrated, community-based care. Can J Gastroenterol 2008; 22(1): 27-32.

16. John-Baptiste A, Varenbut M, Lingley M, et al. Treatment of hepatitis $C$ infection for current or former substance abusers in a community setting. J Viral Hepat 2009. 16(8): 557-567.

17. Grebely J, Genoway K, Khara M, et al. Treatment uptake and outcomes among current and former injection drug users receiving directly observed therapy within a multidisciplinary group model for the treatment of hepatitis $\mathrm{C}$ virus infection. Int J Drug Policy 2007; 18(5): 437-443.

18. Newman AJ, Beckstead S, Beking D, et al. Treatment of chronic hepatitis $C$ infection among current and former drug users within a multidisciplinary treatment model at a community health centre. Can J Gastroenterol 2012; (27)4: 217-223.

19. Charlebois A, Lee L, Cooper E, et al. Factors associated with HCV antiviral treatment uptake among participants of a community-based HCV programme for marginalized patients. J Viral Hepat 2012; 19(12): 836-842.

20. Seidenberg A, Rosemann T, Senn O. Patients receiving opioid maintenance treatment in primary care: successful chronic hepatitis $\mathrm{C}$ care in a real world setting. BMC Infect Dis 2013, 13(9): 1471-2334

21. Litwin $\mathrm{AH}$, Kunins HV, Berg KM, et al. Hepatitis $\mathrm{C}$ management by addiction medicine physicians: results from a national survey. J Subst Abuse Treat 2007 33(1): 99-105.

22. Arora $\mathrm{S}$, Kalishman $\mathrm{S}$, Thornton $\mathrm{K}$, et al. Expanding access to hepatitis $\mathrm{C}$ virus treatment - Extension for Community Healthcare Outcomes (ECHO) project: disruptive innovation in specialty care. Hepatology 2010; 52(3): 1124-1133.

23. Arora S, Thornton K, Murata G, et al. Outcomes of treatment for hepatitis C virus infection by primary care providers. New Engl J Med 2011; 364(23): 2199-2207.

24. Khatri K, Haddad M, Anderson D. Project ECHO: replicating a novel model to enhance access to hepatitis $\mathrm{C}$ care in a community health center. J Health Care for the Poor \& Underserved 2013; 24(2): 850-858.

25. Jack K, Willott S, Manners J, et al. Clinical trial: a primary care-based model for the delivery of anti-viral treatment to injecting drug users infected with hepatitis C. Aliment Pharmacol Ther 2009; 29(1): 38-45.

26. Wilkie BJ. Identifying and managing hepatitis $\mathrm{C}$ in the community. Primary Health Care 2013; 23(4): 22-25

27. Allen SA, Spaulding AC, Osei AM, et al. Treatment of chronic hepatitis $C$ in a state correctional facility. Ann Intern Med 2003; 138(3): 187-190.

28. Farley J, Vasdev S, Fischer B, et al. Feasibility and outcome of HCV treatment in a Canadian federal prison population. Am J Public Health 2005; 95(10): 1737-1739.

29. Remy AJ. [Hepatitis $C$ in prison settings: screening and therapy are improving Comparative survey between 2000 and 2003]. La Presse Medicale 2006; 35(9): 1249-1254. [in French].

30. Gerlich MG, Frick U, Pirktl L, Uchtenhagen A. Detection and treatment of hiv and hepatitis virus infections in Swiss correctional facilities. Int J Public Health 2008; 53: 268-271.

31. Rossaro L, Tran TP, Ransibrahmanakul $K$, et al. Hepatitis $C$ videoconferencing the impact on continuing medical education for rural healthcare providers. Telemed J E Health 2007; 13(3): 269-277

32. National Institute for Health and Clinical Excellence. Telaprevir for the treatment of genotype 1 chronic hepatitis C. NICE technology appraisal guidance 252. 2012. http://www.nice.org.uk/nicemedia/ live/13717/58912/58912.pdf laccessed 3 Nov 2013).

33. National Institute for Health and Clinical Excellence. Boceprevir for the treatment of genotype 1 chronic hepatitis C. NICE technology appraisal guidance 253. 2012. http://www.nice.org.uk/nicemedia/ live/13718/58913/58913.pdf (accessed 3 Nov 2013).

34. Department of Health. Implementing care closer to home: Convenient quality care for patients. Part 3 The accreditation of GPS and Pharmacists with Special Interests. London: DOH, 2007. 